\title{
Lower Gastrointestinal Bleeding: Liver Rams into Gut!
}

\author{
Amit Soni Nirmaljeet Singh Malhi \\ Department of Gastroenterology and Liver Disease, SPS Hospital, Ludhiana, India
}

\section{Keywords}

Colon · Hepatocellular carcinoma - Lower gastrointestinal bleeding

\section{Hemorragia digestiva baixa: Fígado contra o intestino!}

\section{Palavras Chaves}

Colon · Carcinoma hepatocellular · Hemorragia digestiva baixa

A 65-year-old male patient presented to the emergency department with bleeding per rectum for 1 day. $\mathrm{He}$ was diagnosed with hepatitis $\mathrm{C}$ virus-related chronic liver disease (decompensated) with hepatocellular carcinoma (HCC) (BCLC stage D) 3 months back and was on symptomatic treatment. On examination, the patient had tachycardia (pulse rate, $116 / \mathrm{min}$; blood pressure, 90/50 $\mathrm{mm} \mathrm{Hg}$ ), pallor, and icterus. Abdominal examination revealed a large mass in the right upper quadrant. Laboratory tests were as follows: $\mathrm{Hb}, 5.8 \mathrm{~g} / \mathrm{dL}$; TLC, $20.4 \times 10^{9} / \mathrm{L}$; platelets, $90 \times 10^{9} / \mathrm{L}$; total bilirubin, 100.8 $\mu \mathrm{mol} / \mathrm{L}$; serum albumin, $22 \mathrm{~g} / \mathrm{L}$; SGOT, $120 \mathrm{IU} / \mathrm{L}$; SGPT, $54 \mathrm{IU} / \mathrm{L}$; INR, 2; AFP, $633 \mathrm{ng} / \mathrm{mL}$; urea, $34.9 \mathrm{mmol} / \mathrm{L}$; and creatinine, $136.1 \mu \mathrm{mol} / \mathrm{L}$. After initial hemodynamic sta-

\section{KARGER}

E-Mail karger@karger.com www.karger.com/pjg
(C) 2018 Sociedade Portuguesa de Gastrenterologia Published by S. Karger AG, Basel

Karger

0 pen access

This article is licensed under the Creative Commons AttributionNonCommercial-NoDerivatives 4.0 International License (CC BYNC-ND) (http://www.karger.com/Services/OpenAccessLicense). Usage and distribution for commercial purposes as well as any distribution of modified material requires written permission. bilization, a colonoscopy was performed. Colonoscopy documented a large ulcerated lesion $(4 \times 3 \mathrm{~cm})$ near the hepatic flexure suggesting a malignant nature (Fig. 1). Multiple biopsies were taken from the ulcer margin. His previous computed tomography (CT) scan of the abdo-

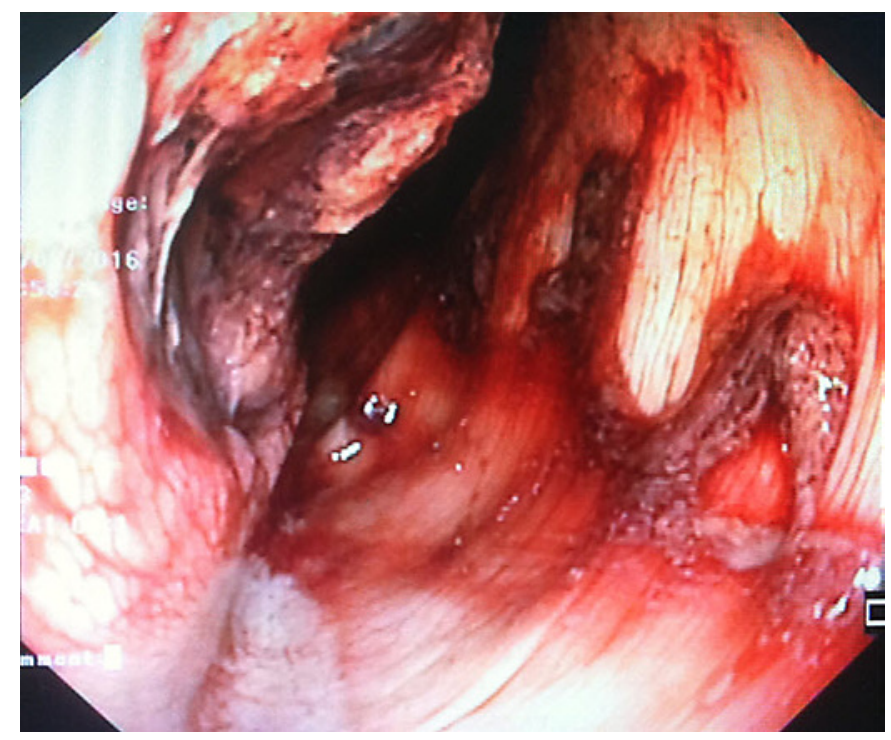

Fig. 1. Colonoscopic image showing a large ulcerated lesion $(4 \times$ $3 \mathrm{~cm}$ ) near the hepatic flexure of the colon along with blood in the lumen.
Dr. Nirmaljeet Singh Malhi

Department of Gastroenterology and Liver Disease SPS Hospital

Ludhiana 141003 (India)

E-Mail drnjsmalhi@gmail.com 
men revealed a large heterogeneous, partly exophytic mass lesion $(12 \times 7 \times 6 \mathrm{~cm})$ in the liver segments IV, V, and VIII with focal disruption of the tumor capsule in the anterior aspect and hyperdense perihepatic fluid (Fig. 2). The lesion was indenting on the right hepatic flexure of the colon. A repeat CT scan of the abdomen was performed, which revealed a large well-delineated air-containing heterogeneous density mass lesion (arising in relation to the liver segments IV, V, and VIII) eroding into and communicating with the adjacent hepatic flexure of the colon (Fig. 3). Multiple well-delineated heterogeneously enhancing hepatic masses of varying sizes were also seen in both liver lobes. Histopathology confirmed the presence of HCC. The patient had a repeat massive lower gastrointestinal (GI) bleed episode and succumbed to death.

This is a rare case as a direct invasion of HCC into the GI tract is uncommon. Most of the extrahepatic metastasis of HCC occurs in patients with advanced-stage intrahepatic tumors. Lungs, abdominal lymph nodes, and bones are the most common sites of extrahepatic metastasis in HCC [1]. Direct invasion to the GI tract by HCC is uncommon, with a reported incidence of approximate-

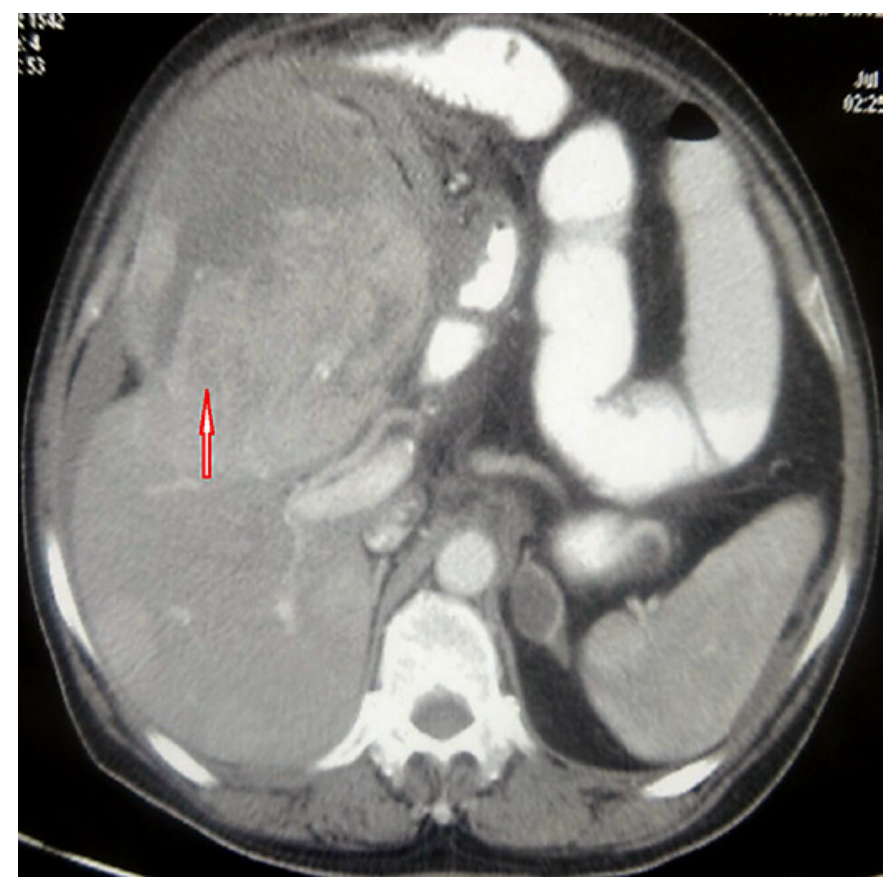

Fig. 2. CT abdomen (axial view) displaying a large heterogenous partly exophytic mass lesion (red arrow) in segments IV, V, and VIII of the liver with focal disruption of the tumor capsule in the anterior aspect and hyperdense perihepatic fluid. The lesion is also indenting on the right hepatic flexure of the colon.

Lower Gastrointestinal Bleeding ly $0.5-2 \%$ among clinical HCC cases $[2,3]$. The most common clinical presentation is frank GI bleeding and the most common site of involvement is the stomach followed by the duodenum and colon $[2,3]$.

Colonic involvement by HCC has been reported in scanty case reports wherein HCC directly invaded into the transverse colon/hepatic flexure and presented with GI bleed. Rare reports with hematogenous spread of HCC to other parts of the colon are also available. Hirashita et al. [4] described 2 similar cases of HCC directly invading into the colon. Both patients underwent partial resection of the liver and colon but they had a very limited survival (1 month and 6 months, respectively). Lin et al. [2] reported 11 cases of GI metastasis in HCC and concluded that prognosis in all the patients was extremely poor. The authors also added that surgical intervention may be the optimal choice for palliative treatment of HCC with GI involvement. In a study from Taiwan, hematogenous spread of HCC to the rectum was seen in a patient who presented with tenesmus [5]. The authors described this as one of the rare cases of hematogenous spread to the colon. Kashani et al. [6] described another rare site of HCC metastasis (i.e., periampullary region). It was diagnosed when a patient (known case of HCC who underwent TACE) was evaluated for low hemoglobin. The authors postulated that the periampullary metastasis was the result of tumor fragments migrating through the biliary tract [6].

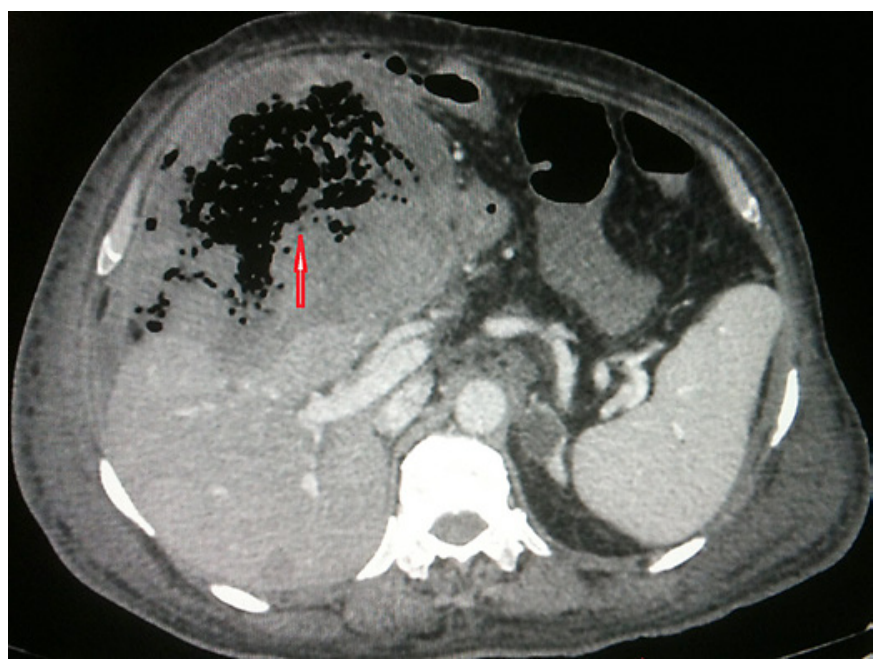

Fig. 3. CT scan of the abdomen (axial view) revealing a large welldelineated air-containing heterogenous density mass lesion (red arrow; arising in relation to segments IV, V, and VIII of the liver) eroding into and communicating with the adjacent hepatic flexure of the colon. 
This study did not require informed consent nor review/approval by the appropriate ethics committee.
The authors have no conflicts of interest to declare.

\section{References}

1 Katyal S, Oliver JH, Peterson MS, Ferris JV, Carr BS, Baron RL: Extrahepatic metastases of hepatocellular carcinoma. Radiology 2000; 216:698-703.

2 Lin CP, Cheng JS, Lai KH, et al: Gastrointestinal metastasis in hepatocellular carcinoma: radiological and endoscopic studies of 11 cases. J Gastroenterol Hepatol 2000;15:536-541.

3 Chen LT, Chen CY, Jan CM, et al: Gastrointestinal tract involvement in hepatocellular carcinoma: clinical, radiological and endoscopic studies. Endoscopy 1990;22:118-123.
4 Hirashita T, Ohta M, Iwaki K, et al: Direct invasion to the colon by hepatocellular carcinoma: report of two cases. World J Gastroenterol 2008; 14:4583-4585.

5 Ou TM, Tsai WC, Hsieh TY, Shih YL: Hepatocellular carcinoma with colonic metastasis. Singapore Med J 2014;55:e93-e95.

6 Kashani A, Nissen NN, Guindi M, Jamil LH: Metastatic periampullary tumor from hepatocellular carcinoma presenting as gastrointestinal bleeding. Case Rep Gastrointest Med 2015;2015:732140. 